\title{
PERANCANGAN SISTEM MANAJEMAN ADMINISTRASI DAN PENGINGAT KONTRAK KARYAWAN PADA PT. PUTRA DUMAS LESTARI
}

\author{
Harfizar $^{1}$, Janu Ilham Saputro ${ }^{2}$, Agus Sofyan ${ }^{* 3}$ \\ ${ }^{1,2,3}$ Program Studi Sistem Informasi Fakultas Sains dan Teknologi Universitas Raharja \\ Email : ${ }^{1}$ harfizar@ raharja.info, ${ }^{2}$ januilham@yahoo.com, ${ }^{* 3}$ agus@ raharja.info
}

\begin{abstract}
Abstrak
Karyawan kontrak atau sering juga disebut karyawan tidak tetap, umumnya terikat hubungan kerja dengan perusahaan untuk pekerjaan dengan keahlian tertentu, atau jangka waktu tertentu. Sistem kontrak karyawan yang berjalan saat ini pada PT Putra Dumas lestari masih terdapat kekurangan diantaranya perpanjang kontrak kerja karyawan, karena untuk membuat surat perpanjang kontrak harus merekap data karyawan kontrak secara satu persatu, belum adanya program pengingat masa kontrak karyawan sehingga HRD terlambat dalam memperbaharui kontrak karyawan. Sehingga diperlukan adanya perancangan sistem informasi kontrak kerja khusus untuk menunjang kegiatan pembuat kontrak dan perpanjang kontrak. Dalam proses penyusunan laporan. Penelitian ini menggunakan metode analisa PIECES (Performance, Information/Data, Economy, Control, Efficiency, Service), elisitasi kebutuhan sistem, serta pemodelan sistem dengan menggunakan UML (Unified Modelling Language) untuk menggambarkan secara visualisasi, yang selanjutnya diimplementasikan dengan bahasa pemrograman Hypertext Preprocessor (PHP) dengan basis data MySQL sebagai database yang digunakan. Dengan adanya sistem informasi kontrak kerja dapat mempermudah HRD dalam pembuatan kontrak, perpanjang kontrak dan menghasikan laporan yang akurat dengan waktu yang cepat, sehingga menciptakan kinerja yang efektif dan efisien, serta dapat menunjang pengendalian kontrak kerja bagi pimpinan terhadap laporan yang dihasilkan sebagai bahan pengambilan keputusan kedepannya.
\end{abstract}

Kata Kunci - kontrak kerja, HRD, PHP, Mysql.

\begin{abstract}
Contract employees often called non-permanent employees, are general ly tied to work for a job with a particular skill, or a certain period of time. The current employee contract system in PT Putra Dumas sustainably still lacks such as extending the employment contract, because to make contract extension letter must recruit employee contract data one by one, there is no reminder program for employee contract period so HRD is late in renewing employee contract. Therefore, it is necessary to design a special contract information system to support contractor and contract extension activities. In the process of preparing the report. This research uses PIECES analysis method (Performance, Information / Data, Economy, Control, Efficiency, Service), system requirement elicitation, and system modeling using UML (Unified Modeling Language) to visualize, then implemented with programming language Hypertext Preprocessor (PHP) with MySQL database as the database used. With the information system contract work can facilitate HRD in making contracts, extend contracts and produce accurate reports with a fast time, thereby creating an effective and efficient performance, and can support control of contracts for the employee leadership report generated as a decision-making materials going forward.
\end{abstract}

Keywords-employment contract, HRD, PHP, MySQL. 


\section{PENDAHULUAN}

PT. Putra Dumas Lestari merupakan salah satu perusahaan yang bergerak dalam bidang jasa kontruksi isolasi pemanas, PT. Putra Dumas Lestari terletak didaerah Jakarta BaratCengkareng. Karyawan kontrak atau sering juga disebut karyawan tidak tetap, umumnya terikat hubungan kerja dengan perusahaan untuk pekerjaan dengan keahlian tertentu, atau jangka waktu tertentu. Hubungan kerja antara perusahaan dan karyawan kontrak tidak bersifat permanen, hal ini disebabkan karena sifat pekerjaan yang biasanya sekali selesai. Jika keahlian atau tenaga karyawan kontrak tidak lagi dibutuhkan, maka hubungan kerja diantara keduanya dapat berakhir sesuai jangka waktu kontrak.

Sistem kontrak karyawan yang berjalan saat ini masih terdapat kekurangan diantaranya perpanjang kontrak kerja karyawan, karena untuk membuat surat perpanjang kontrak harus merekap data karyawan kontrak secara satu persatu, belum adanya program pengingat masa kontrak karyawan sehingga HRD terlambat dalam memperbarui kontrak karyawan.

\section{RUMUSAN MASALAH}

Berdasarkan latar belakang yang telah dijelaskan di atas, maka dirumuskan beberapa masalah sebagai berikut:

1. Bagaimana sistem pengolahan Kontrak karyawan PT. Putra Dumas Lestari yang berjalan saat ini?

2. Kendala - kendala apa saja yang terjadi pada sistem kontrak karyawan yang berjalan saat ini ?

3. Bagaimana merancang sistem manajemean administrasi dan pengingat kontrak karyawan yang sesuai dengan kebutuan perusahan?

\section{METODE PENELITIAN}

Untuk mendapatkan data dan keterangan yang diperlukan dalam penelitian ini digunakan beberapa metode adalah sebagai berikut:

\section{Metode Pengumpulan Data}

Untuk memperoleh data-data yang dibutuhkan guna menyusun Skripsi ini, maka penulis melakukan penelitian. Adapun metodologi penelitian yang saling berhubungan dalam menyajikan penulisan ini sebagai berikut :

1. Metode Observasi (Observation Research)

Peneliti melakukan pengamatan langsung ke PT. Putra Dumas Lestari terletak didaerah Jakarta Barat- Cengkareng. guna mendapatkan data dan informasi serta mengetahui permasalahan atau Kendala yang dihadapi dalam proses yang sedang berjalan.

2. Metode Wawancara (Interview Research)

Peneliti melakukan sesi wawancara langsung dan mengajukan pertanyaan-pertanyaan kepada Bapak Bernandus, guna mendapatkan data dan informasi yang dibutuhkan.

3. Metode Studi Pustaka (Library Research)

Peneliti membaca buku-buku atau jurnal yang berhubungan dengan pembahasan sebagai bahan referensi.

\section{Metode Analisa Sistem}

Dalam tahap analisa sistem, diambil langkah langkah analisis data agar mendapatkan hasil yang bermanfaat dan relevan dengan menggunakan metode Analisa PIECES (Performance, Information/ Data, Economic, Control/ Security, Efficiency, and Service).

\section{Metode Perancangan}

Pada sistem ini penulis melakukan metode perancangan menggunakan metode UML (Unified Modeling Language) karena dengan menggunakan metode UML, rekayasa dan 
pengembangan perangkat dapat dilakukan dengan fokus pengembangan dan desain perangkat lunak. Dalam UML ini diagram yang digunakan antara lain :

1. Use Case Diagram

2. Activity Diagram

3. Sequence Diagram

4. Class Diagram

\section{Metode Pengujian/Testing}

Dalam penelitian ini metode pengujian yang digunkaan yaitu blackbox testing. metode pengujian ini adalah cara atau teknik yang digunakan untuk menguji perangkat lunak, dan untuk mengetahui kualitas dari suatu sistem yang dilakukan untuk mengeliminasi suatu kesalahan yang terjadi.

\section{LANDASAN TEORI}

\section{Definisi Sistem}

Menurut Abidin yang dikutip oleh Priyo Sutopo, Dedy Cahyadi, Zainal Arifin (2016:24). "suatu kesatuan yang terdiri komponen atau elemen yang dihubungkan bersama untuk memudahkan aliran informasi, materi atau energi".

\section{Definisi Informasi}

Menurut M.Thoha dan Miyanto (2015:1). "Informasi adalah data yang telah diolah menjadi sebuah bentuk yang berarti bagi penerimaan dan bermanfaat dalam mengambil keputusan saat ini atau mendatang. Informasi adalah data yang diolah menjadi bentuk yang lebih berguna dan lebih berarti bagi yang menerimanya".

\section{Definisi Sistem Informasi}

Menurut M.thoha dan Miyanto (2015:2). "Sistem Informasi adalah sekumpulan prosedur yang terogarnisir dan di jalankan guna dapat menyediakan infromasi untuk menunjang atau mendukung organinasi. Sistem informasi memiliki definisi yang berbeda menurut para ahli, namun secara umum, sistem informasi adalah kombinasi dari teknologi informasi dan aktivitas orang yang menggunakan teknologi itu untuk mendukung operasi dan manajemen".

\section{Definisi Perancangan Sistem}

Menurut kausar dkk dalam jurnal PROSISKO (2015:22). "perancangan adalah pengembangan system dari dari sistem yang sudah ada atau sistem yang baru, dimana masalah-masalah yang terjadi pada sistem yang lama diharapkan sudah teratasi pada sistem yang baru".

\section{Definisi Absensi}

Absensi adalah suatu pendataan kehadiran, bagian dari pelaporan aktivitas suatu institusi, suatu komponen institute itu sendiri yang berisi data-data kehadiran yang disusun dan diatur sedemikian rupa sehingga mudah untuk dicari dan dipergunakan apabila sewaktu-waktu di perlukan oleh pihak yang berkepentingan.

\section{Definisi Web}

Menurut Priyo Sutopo, dkk. (2016:25). "Web merupakan terobosan baru sebagai teknologi sistem informasi yang menghubungkan data dari banyak sumber dan layanan yang beragam macamnya di internet, Web cepat sekali populer di lingkungan pengguna internet, karena kemudahan yang diberikan kepada pengguna internet untuk melakukan penelusuran, penjelajahan, dan pencarian informasi".

\section{Definisi Database}

Menurut Maimunah, Dini Luigi, dan Ade Ferdiansyah (2017:2). "Database adalah sebuah struktur yang umumnya dikategorikan dalam 2 (dua) hal, sebuah database flat dan sebuah database relasional. Database relasional lebih disukai karena lebih masuk akal dibandingkan database flat".

\section{Definisi PHP}

Menurut Rosa, A. S. dan M.Shalahuddin (2016:2). "PHP merupakan bahasa pemograman untuk membuat website yang bersifat server-side scripting, PHP memungkinan anda untuk membuat halaman website yang bersifat dinamis" 


\section{LITERATURE REVIEW}

Berikut ini adalah penelitian yang telah dilakukan dan memiliki korelasi yang searah dengan penelitian yang akan dibahas, antara lain:

1. Penelitihaan yang dilakukan oleh Melani, Melavi (2017) berjudul PERANCANGAN SISTEM PENYIMPANAN ARSIP DOKUMEN PERJANJIAN KONTRAK KERJA BERBASIS MICROSOFT VISUAL FOXPRO9.0PADA PT. ANDALAN MITRA PRESTASI PADANG peneliti membahas pengarsipan dokumen perjanjian kontrak kerja pada Business Development Department PT Andalan Mitra Prestasi dengan Microsoft Visual Foxpro9.0 dan mengaplikasikan rancangan sistem penyimpanan arsip. Metode penelitian yang digunakan metode eksperimen degan cara menguraikan kondisi yang sebenarnya terjadi dalam perusahaan yang berpedoman pada teori-teori yang relevan.Hasil penelitian ini menunjukkan bahwa sistem penyimpanan arsip yang digunakan saat ini kurang efisien dan memakan waktu yang cukup lama dalam menyajikan informasi, makaperlunya sistem penyimpanan arsip bebasis Microsoft Visual Foxpro9.0 yang dapat digunakan untuk mengurangi waktu yang terpakai. Sistem ini dapat memudahkan karyawan dalam melakukan penginputan dokumen perjanjian kontrak kerja, pencarian dan memperbaiki dokumen perjanjian kontrak kerja serta penyimpanan arsip secara elektronik. Data yang dibuat dalam sistem penyimpanan arsipini yaitu: data login, data dokumen perjanjian kontrak kerja.

2. Penelitihaan yang dilakukan oleh Rina Safitri Lubis dalam jurnal Informasi dan Teknologi Ilmiah (INTI) yang berjudul: DATA MINING PENGARSIPAN DOKUMEN BERDASARKAN KONTRAK KERJA DENGAN METODE ALPHABE TICFILING SYSTEM tahun 2014 peneliti membahasa Kearsipan merupakan kumpulan dari dokumen dan dapatmemberikan keterangan atau bukti yangberkaitan dengan proses pengumpulan dan pengelolaandokumen. PT. Arina Multikarya Medan adalah sebuahperusahaan yang bergerak di bidang outsourcing. PT.Arina Multikarya Medan ini mempunyai karyawan(kontrak kerja) yang cukup banyak. Oleh karena karyawan yang cukup banyak, maka dokumen karyawantersebut harus teroganisir dengan baik terutama dalam dokumentasi karyawan berdasarkan kontrak kerja.

3. Penelitihan yang dilakukan Mawarizka Deviera, Sulistiowati, dan ulianto Lemantara dalam jurnal issn berjudul : RANCANG BANGUN SISTEM INFORMASI ADMINISTRASI KEPEGAWAIAN PADA PT. PANCARAN SEMANGAT JAYA tahun 2015 peneliti membahas "PT. Pancaran Semangat Jaya adalah perusahaan yang bergerak di bidang bahasa Jawa penerbitan majalah bernama "Panjebar Semangat" yang pertama kali diterbitkan pada tahun 1933 hingga sekarang. Saat ini, administrasi kepegawaian adalah dilakukan oleh bagian administrasi dan dokumentasi dicatat secara manual dan hasilnya diedit menggunakan Microsoft Word dan Microsoft Excel aplikasi, lalu dicetak dan disimpan dalam penyimpanan. Ini mengarah pada proses pencarian data dan periksa, begitu juga maraja laporan yang mengurangi jam kerja bagi karyawan. Berbasis pada masalah, solusi" ditawarkan dalam bentuk sistem informasi administrasi kepegawaian itu akan menghubungkan karyawan di setiap divisi di dalam perusahaan dengan menggunakan dnaklien berdasarkan server dan metode air terjun. Metode ini menggunakan pendekatan sistematis dan rentang serial dari tingkat kebutuhan sistem dan menuju ke tahap analisis, desain, pengkodean, pengujian dan pemeliharaan. Hasil penelitian ini menunjukkan bahwa administrasi kepegawaian sistem informasi dapat membantu PT. Pancaran Semangat Jaya untuk merekam dan memproses data dengan cepat dan benar.

4. Penelitihan yang dilakukan oleh Hamidah, Eko Purnomo, dan Moh. Faid dalam jurnal Prosiding sentia yang berjudul : SISTEM APLIKASI PENGOLAHAN DATA KONTRAK MATERIAL DAN JASA BERBASIS WEB DI KOPKAR MITRA ENERGI SEJAHTERA PAITON tahun 2016 peneliti membahas Proses transaksi kontrak material dan jasa antara customer, koperasi dan supplier diKopkar Mitra Energi Sejahtera Paiton awalnya menggunakan surat jalan. Apabila costumer membutuhkan barang, maka costumer akan 
memberikan surat kebutuhan barang tersebut kepada koperasi. Begitu pula sebaliknya dengan koperasi. Untuk menanyakan harga dari barang yang dibutuhkan oleh costumer kepada supplier juga menggunakan surat jalan atau via email. Sehingga membutuhkan banyak tenaga untuk melakukan transaksi kontrak tersebut serta banyak pekerjaan yang terbengkalai . Oleh karena itu penulis saat ini ingin membuat sistem yang sedang berjalan ke sistem web yang nantinya akan mempermudah proses transaksi antara costumer, koperasi dan supplier sehingga proses transaksi kontrak material dan jasa tersebut dapat dilakukan di masing-masing kantor. Sistem yang dibuat ini juga di lengkapi dengan laporan setiap bulan dan setiap tahunnya. Sehingga manager koperasi bisa mengetahui proses kontraknya.

5. Penelitihaan yang dilakukan oleh Titik Rahmawati dalam jurnal TEKNOMATIKA yang berjudul : PERANCANGAN SISTEM PENGELOLAAN DOKUMEN ELEKTRON IKDI BIDANG AKADEMIK STMIK JENDERAL ACHMADYANI YOGYAKARTA 2015 peneliti membahas Kegiatan pengelolaan dokumen di bidang akademik STMIK JenderalAchmad Yani Yogyakarta telah menjadi kegiatan yang rutin dan pentingdilakukan. Hal inidikarenakan dokumen-dokumen ini telah menjadi bagian yangsangat penting untuk kelangsungan karir dosen maupun untuk kepentinganakreditasi prodi maupun institusi.Penelitian ini merupakan salah satu bagian dari penelitian yang berupayamerancang dan membangun sebuah prototipe sistem pengelolaan dokumendigital yang disesuaikan untuk kebutuhan akreditasi dan pelaporan kinerja dosen.Penelitian ini dilakukan dengan metode wawancara dan pengamatan langsungterhadap proses dan kebutuhan dokumen di bidang akademik STMIK JenderalAchmad Yani.Penelitian ini mendapati bidang akademik belum memiliki sebuah sistemdan SOP yang khusus menangani tentang dokumentasi yang berhubungan dengan kepentingan akreditasi dan beban kinerja dosen.

6. Penelitian yang dilakukan oleh Ahmed Javed yang berjudul "IMPACT OF EMOTIONAL INTELLIGENCE ON EMPLOYEE PERFORMANCE IN PROJECT MANAGEMENT" This study examined the impact of emotional intelligence on employee per-formance in project management. This research also investigated the medi-ating effect of work engagement and moderating effect of project managerscompetence amongst the emotional intelligence and project employee perfor-mance. Data was collected from the organizations involved in constructionprojects, situated in Islamabad and Rawalpindi. For the data collection, con-venient sampling technique was used. Responses from employees and theirsupervisors were recorded separately through the distributed questionnaires.Out of 250 distributed questionnaires, 220 were retrieved. The findings of theresearch suggest that the work engagement significantly but partially medi-ates the relationship between emotional intelligence and project employee per-formance.

\section{HASIL DAN PEMBAHASAN}

\section{Usulan Prosedur Yang Baru}

Berdasarkan analisa serta penelitian yang telah dilakukan dalam sistem yang berjalan di bagian kepegawaian pada PT. Putra Dimas Lestari, maka tahap selanjutnya yaitu membahas sistem yang akan diusulkan. Adapun sistem yang diusulkan akan membantu HRD dalam mengelola data kontrak, pembuatan surat perjanjian dan perpanjangan kontrak. Sistem berjalan saat ini masih menggunakan microsoft office untuk mengelola data sehingga belum berjalan secara maxsimal karena masih terdapat beberapa kesalahan pada saat proses perpanjangan kontrak. Berdasarkan permasalahan yang ada maka penulis bermaksud membangun sistem yang berguna untuk bagian kepegawaian agar dapat memudakan dalam proses penyusunan laporan pembuatan kontrak dan perpanjangan kontrak. 


\section{Diagram Rancangan Sistem}

Adapun diagram-diagram usulan pada penelitian ini digambarkan dalam program Visual Paradigm for UML Enterprise Edition Ver. 6.4 adalah sebagai berikut:

\section{Use Case Diagram Yang Diusulkan}

Use case diagram berfungsi untuk menggambarkan hubungan interaksi antara sistem dan si pemakai.

\section{Use Case Diagram Sistem Kontrak}

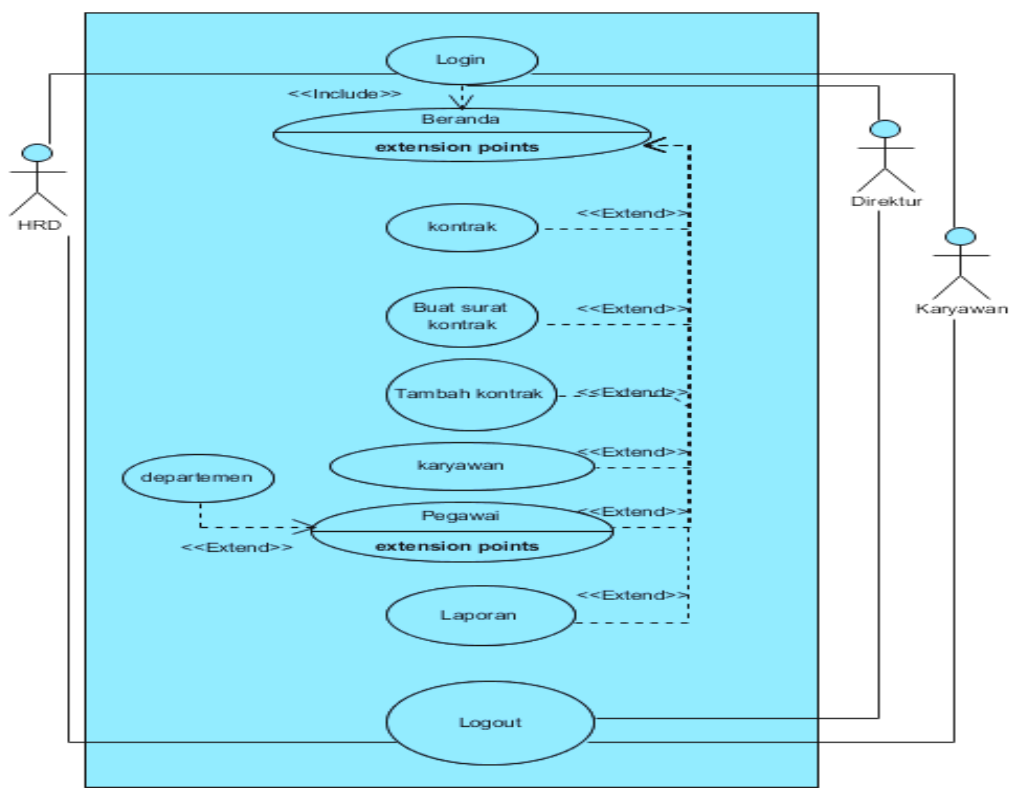

Gambar 1. Use Case Diagram Yang Diusulkan Untuk Sistem Kontrak

Berdasarkan Gambar 1. Use Case Diagram Yang Diusulkan Untuk Sistem Kontrak terdapat :

a. Terdapat 1 sistem yang mencakup seluruh sistem kontrak

b. Terdapat 4 Actor yang melakukan kegiatan, yaitu : HRD, Direktur, Karyawan dan Admin

c. Terdapat 10 use case yang dapat dilakukan oleh Actor

d. Terdapat 1 Include di dalam sistem

e. Terdapat 7 Extend di dalam sistem

\section{Activity Diagram sistem Kontrak}

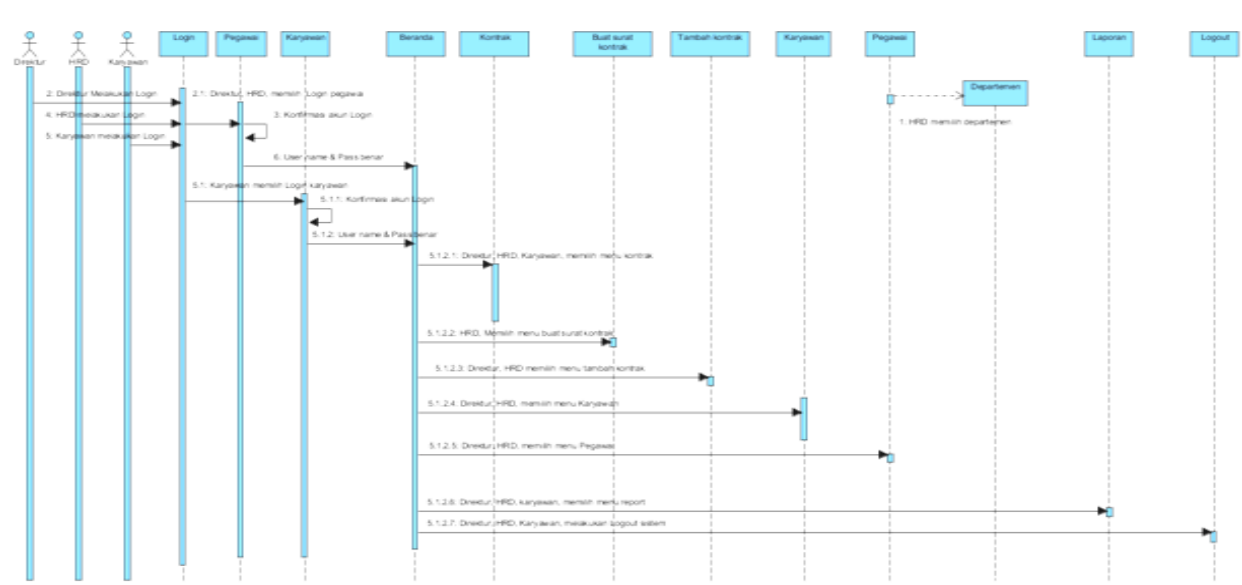

Gambar 2. Sequence Diagram Sistem Kontra 
Berdasarkan gambar Sequence Diagram diatas terdapat :

a. 3 actor, yang melakukan kegiatan yaitu Admin, Staff Keuangan, Bagian Umum, dan Kasubid Keuangan.

b. 14 life line, objek entity antar muka yang saling berinteraksi.

c. 21 mesangge, spesifikasi dari komunikasi antar objek yang membuat informasi-informasi aktifitas yang terjadi.

\section{Activity Diagram Sistem Kontrak}

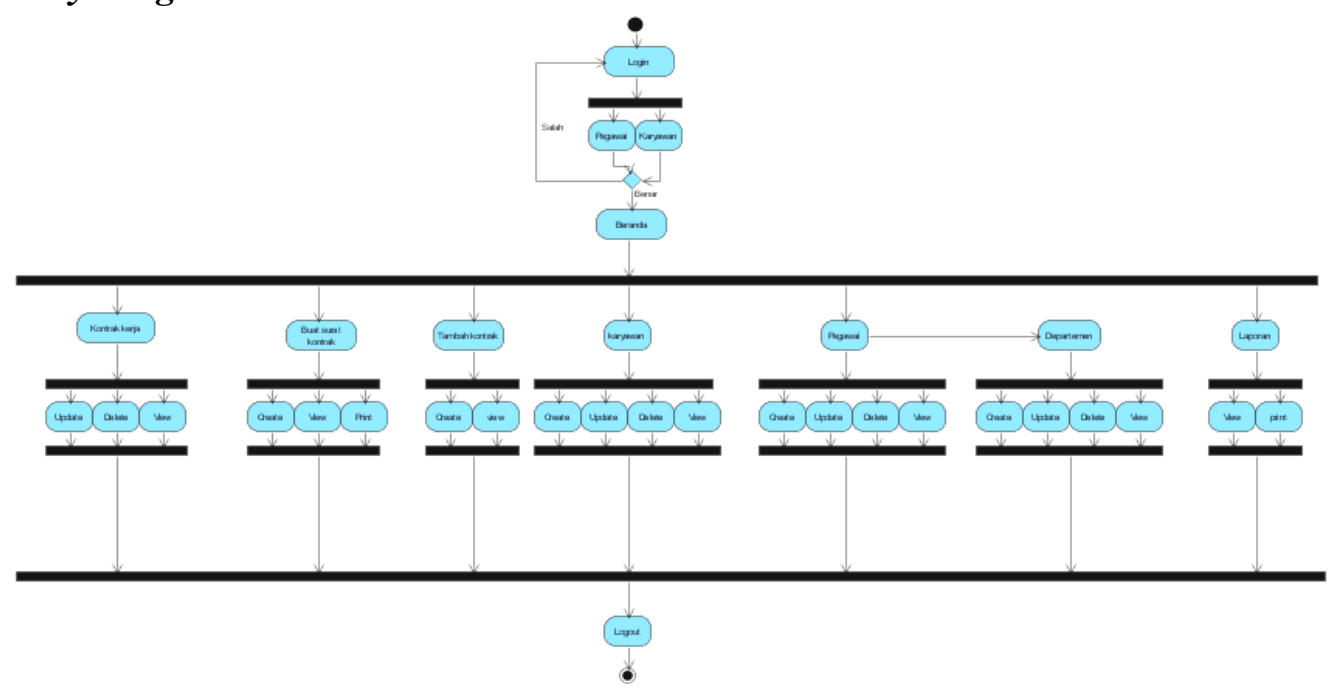

Gambar 3. Activity Diagram Yang Diusulkan Untuk Sistem Kontrak

Berdasarkan Gambar 2. Activity Diagram Yang Diusulkan Untuk Siem Kontrak terdapat :

a. 1 initial Node, objek yang diatas diawali

b. 40 Action, dari sistem yan mencerminkan eksekusi dari suatu aksi.

c. 1 Decesion Node, merupakan pemilihan ya atau tidak.

d. 11 Forknode yang merupakan pilihan dari action tersebut.

e. 11 Joinnode yang merupakan gabungan dari beberapa activity yang paralel.

f. 1 Activity Final Node, objek yang diakhiri.

\section{Class Diagram yang Diusukan}

Class Diagram dapat membantu untuk memvisualisasikan kelas dari suatu sistem, karena class digram memiliki kelompok objek dengan atribut (property) dan relasi yang sama.

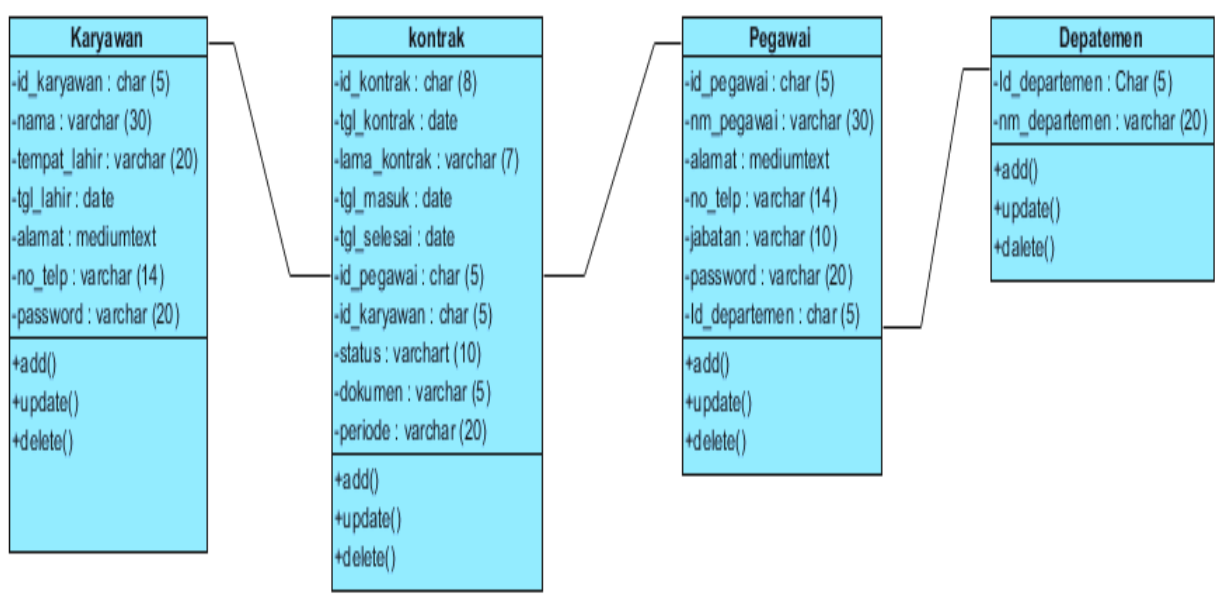

Gambar 4. Class Diagram Yang Diusulkan 
SPESIFIKASI BASIS DATA

Tabel 1. Tabel Karyawan

\begin{tabular}{|l|l|l|l|l|}
\hline No & Field Name & Data Type & Field Siz & Keterangan \\
\hline 1 & Id_karyawan & Char & 5 & IdKaryawan \\
\hline 2 & Nama & Varchar & 30 & NamaKaryawan \\
\hline 3 & Tempat_lahir & Varchar & 20 & TempatLahir \\
\hline 4 & Tgl_lahir & Date & 8 & TanggalLahir \\
\hline 5 & Alamat & Mediumtext & - & Alamat \\
\hline 6 & No-telp & Varchar & 13 & NomorTelpon \\
\hline 7 & Password & Varchar & 6 & Password \\
\hline
\end{tabular}

Tabel 2. Tabel Kontrak

\begin{tabular}{|lll|l|l|l|}
\hline No & Field Name & Data Type & Field Size & Keterangan \\
\hline 1 & id_kontrak & Char & 8 & Id Kontrak \\
\hline 2 & Tgl_kontrak & Date & 8 & TanggalKontrak \\
\hline 3 & kontrak & Varchar & 2 & LamaKontrak \\
\hline 4 & asuk & Date & 8 & $\begin{array}{l}\text { TanggalMasukK } \\
\text { ontrak }\end{array}$ \\
\hline 5 & lesai & Date & 8 & $\begin{array}{l}\text { TanggalSelesaiK } \\
\text { ontrak }\end{array}$ \\
\hline 6 & awai & Char & 5 & IdPegawai \\
\hline 7 & yawan & Char & 5 & IdKaryawan \\
\hline 8 & & Varchar & 10 & Status \\
\hline 9 & nen & Varchar & 5 & $\begin{array}{l}\text { DokumenKontra } \\
\text { k }\end{array}$ \\
\hline 10 & 2 & Varcar & 20 & $\begin{array}{l}\text { PeriodeWaktuKo } \\
\text { ntrak }\end{array}$ \\
\hline
\end{tabular}

Tabel 3. Tabel Pegawai

\begin{tabular}{|l|l|l|l|l|}
\hline No & Field Name & Data Type & Field Size & Keterangan \\
\hline 1 & Id_pegawai & Char & 5 & IdPegawai \\
\hline 2 & Nm_pegawai & Varchar & 30 & NamaPegawai \\
\hline 3 & Alamat & Mediumtext & - & Alamat \\
\hline 4 & No_telp & Varchar & 13 & NomorTelepon \\
\hline 5 & Jabatan & Varchar & 8 & Jabatan \\
\hline 6 & Password & Varchar & 6 & Password \\
\hline
\end{tabular}

Tabel 4. Tabel Departemen

\begin{tabular}{|l|l|l|l|l|}
\hline No & Field Name & Data Type & Field Size & Keterangan \\
\hline 1 & Id_Departemen & Char & 5 & IdDepartemen \\
\hline 2 & Nm_Departemen & Varchar & 20 & NamaDepartemen \\
\hline
\end{tabular}




\section{IMPLEMENTASI}

1. Rancangan Tampilan Program

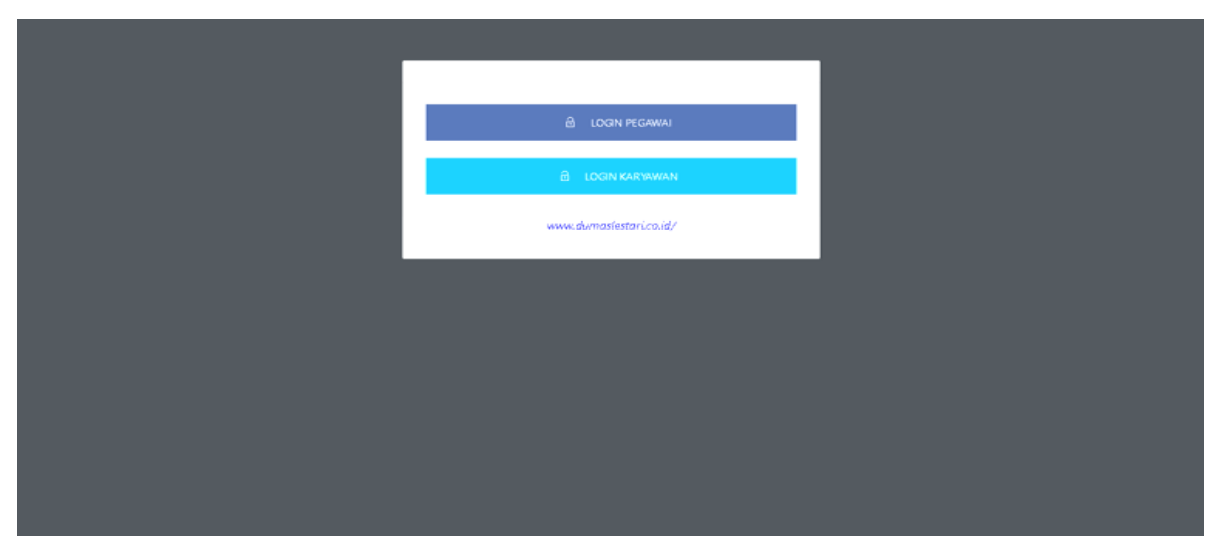

Gambar 5. Tampilan Halaman Login

Tampilan diatas merupakan tampilan awal sebelum masuk ke dalam sistem.

\section{Rancangan Tampilan Login Pegawai}

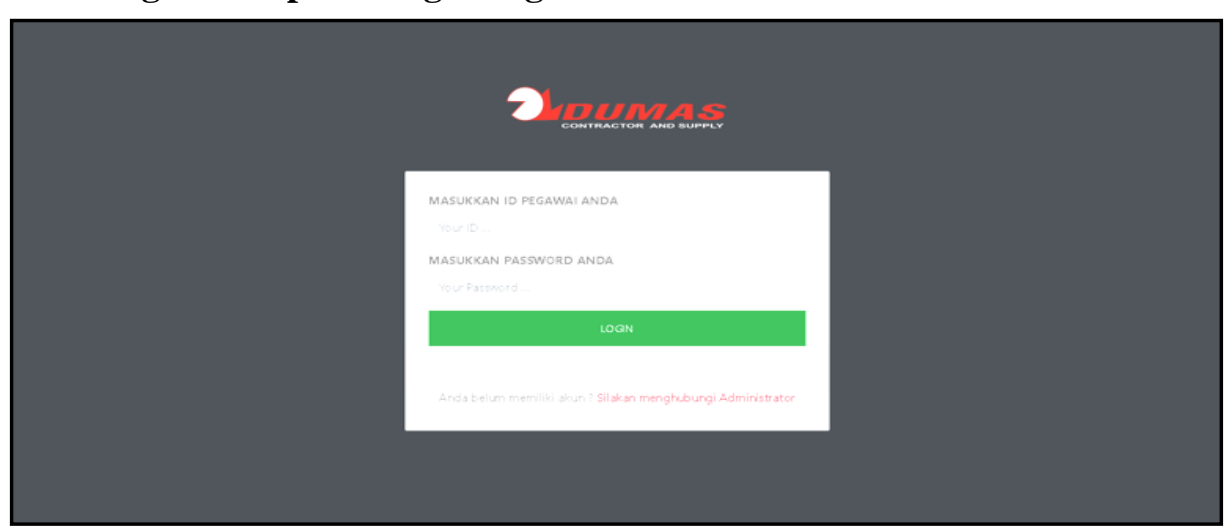

Gambar 6. Tampilan Halaman Login Pegawai

Tampilan diatas merupakan tampilan login pegawai sebelum masuk kedalam sistem, setiap user harus melakukan login dengan memasukan username dan password yang benar agar dapat masuk kedalam sistem.

\section{Rancangan Tampilan Login Karyawan}

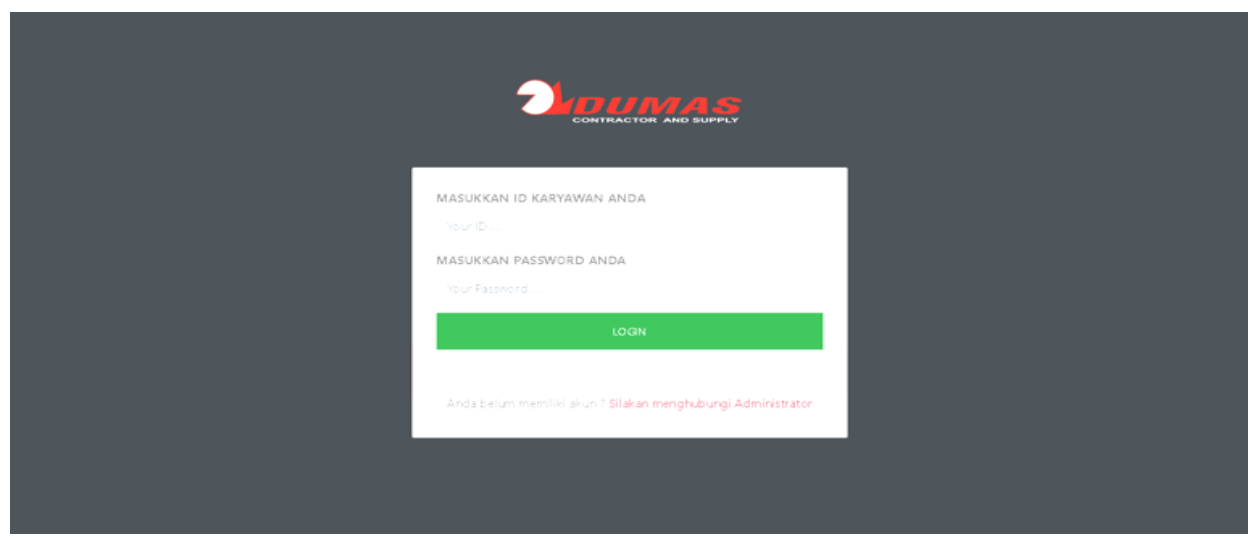

Gambar 7. Tampilan Login Karyawan 
Tampilan diatas merupakan tampilan login karyawan sebelum masuk kedalam sistem, setiap user harus melakukan login dengan memasukan username dan password yang benar agar dapat masuk kedalam sistem.

\section{Rancangan Tampilan Halaman Beranda}

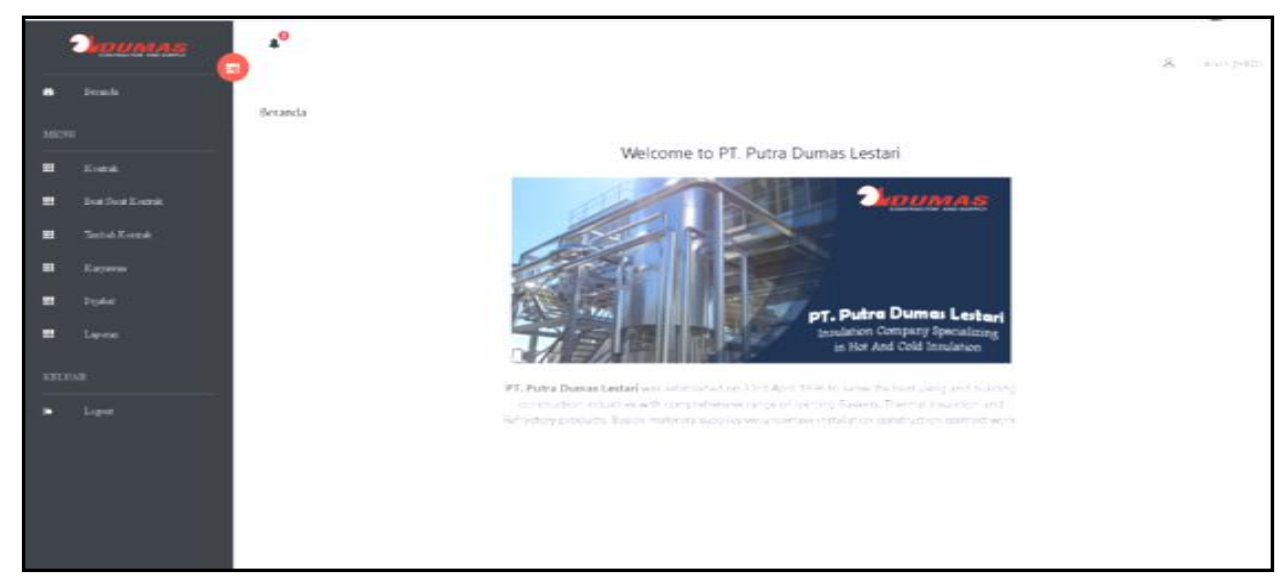

Gambar 8. Tampilan Halaman Beranda

Setelah user melakukan proses login dengan benar, maka akan tampil dashboard yang mana didalamnya menggambarkan Kontrak kerja yang telah diinput dalam suatu periode tertentu.

\section{Rancangan Tampilan Halaman Kontrak}

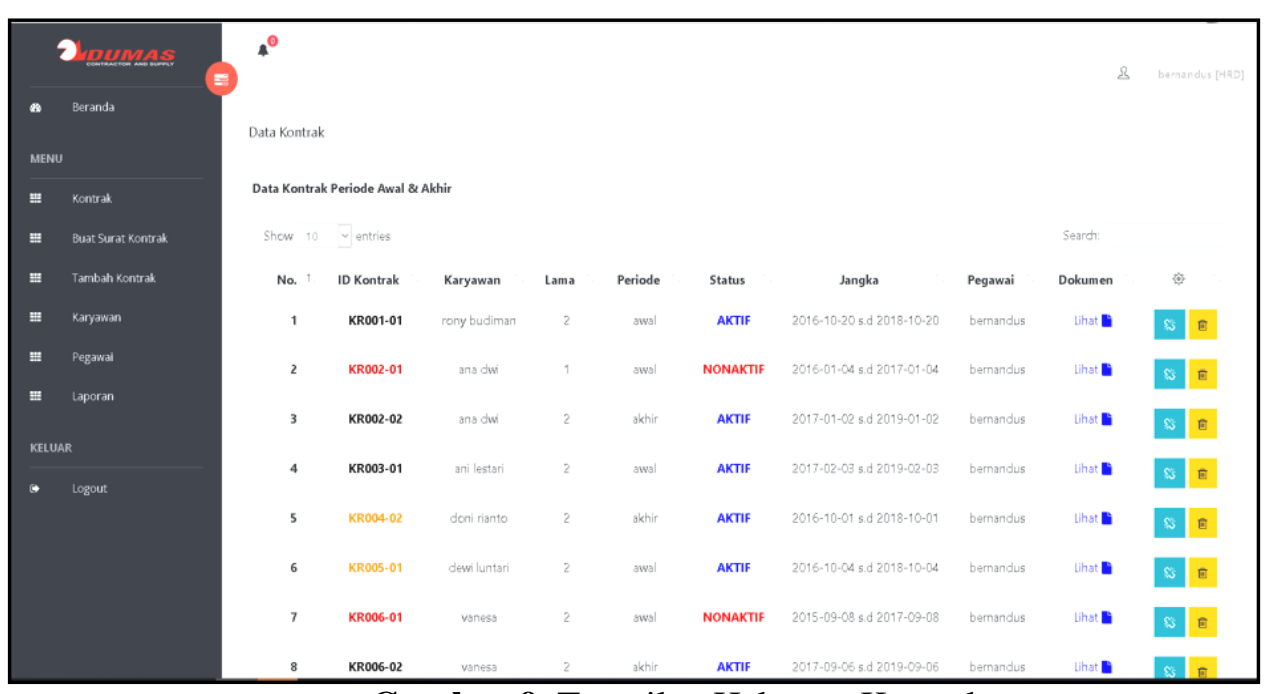

Gambar 9. Tampilan Halaman Kontrak

Tampilan diatas adalah tampilan dari halaman kontrak yang didalamnya terdapat data kontrak kerja. Dihalaman ini user dapat melakukan, liat dokumen perjanjian kerja , edit data, hapus data. 


\section{Rancangan Tampilan Tambah Kontrak}

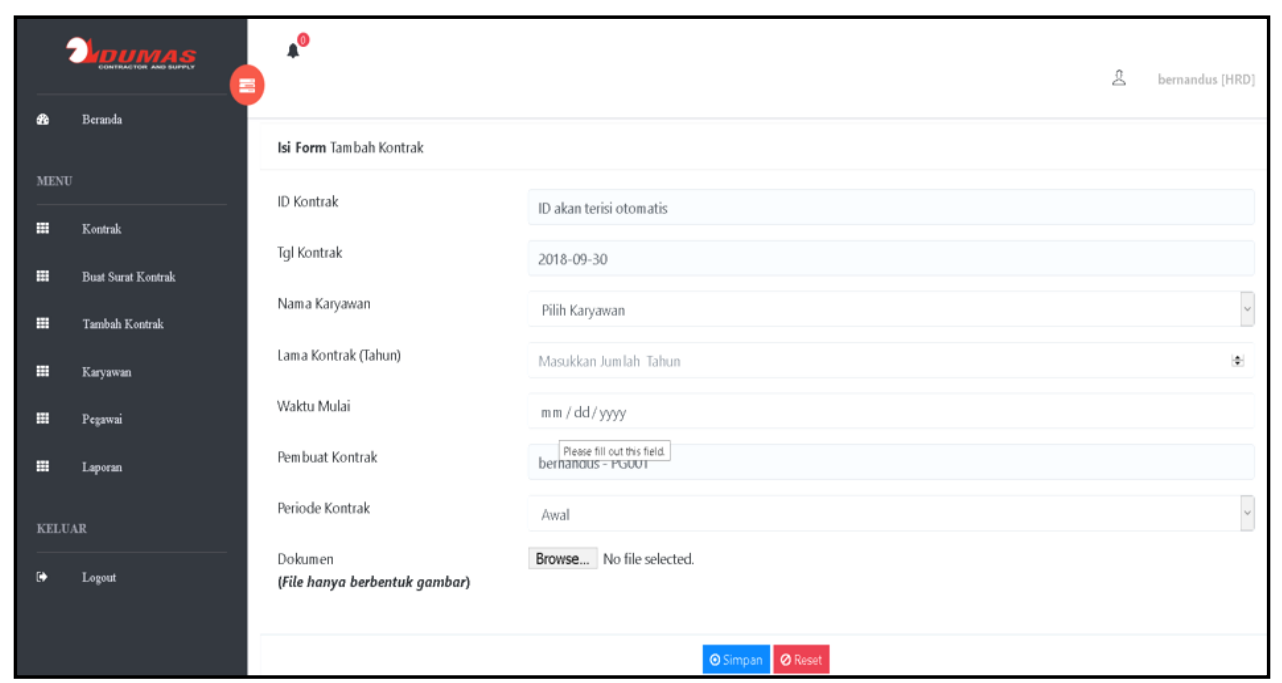

Gambar 10. Tampilan Halaman Tambah Kontrak

Tampilan diatas, merupakan tampilan form input data kontrak kerja yang mana user dapat memilih nama, tanggal masuk tanggal kontrak, lama kontrak, tanggal selisai, periode, upload file surat perjanjian. Jika semua data terisi maka akan tersimpa.

\section{Tampilan Halaman Karyawan}

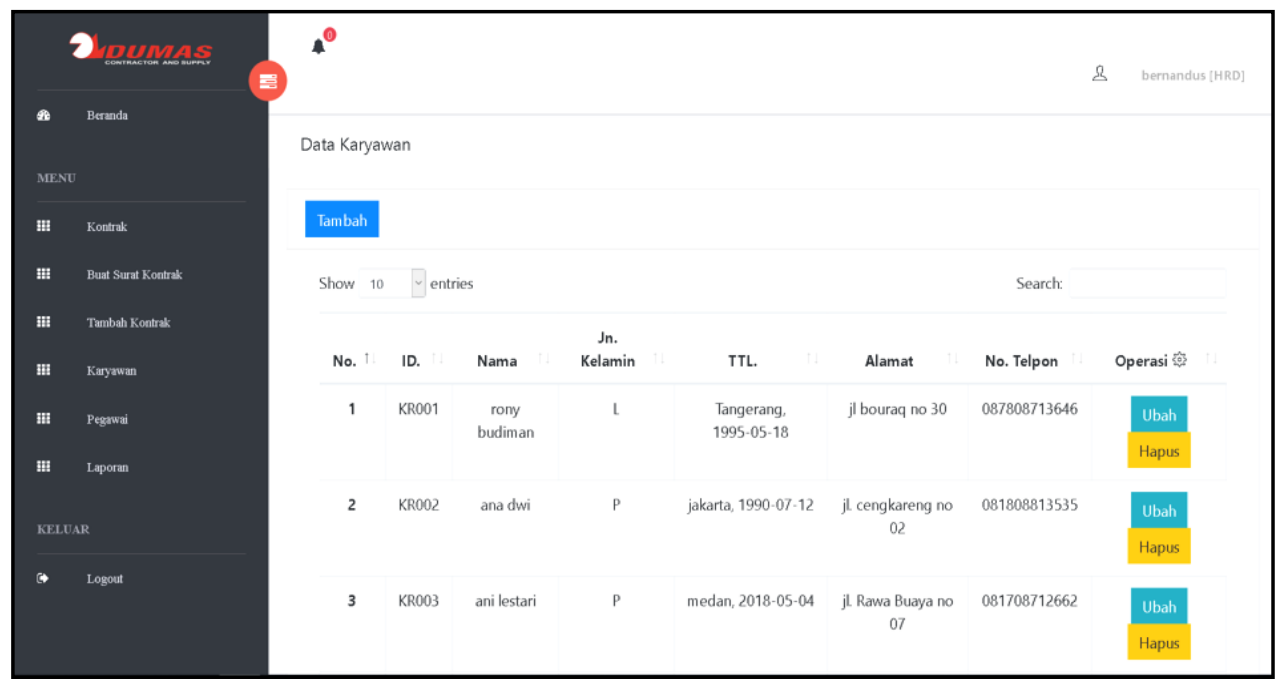

Gambar 11. Tampilan Halaman Karyawan

Tampilan diatas adalah tampilan dari halaman karyawan yang didalamnya terdapat data karyawan. Dihalaman ini user dapat melakukan tambah data, edit data, hapus data. 


\section{Tampilan Halaman Input Departemen}

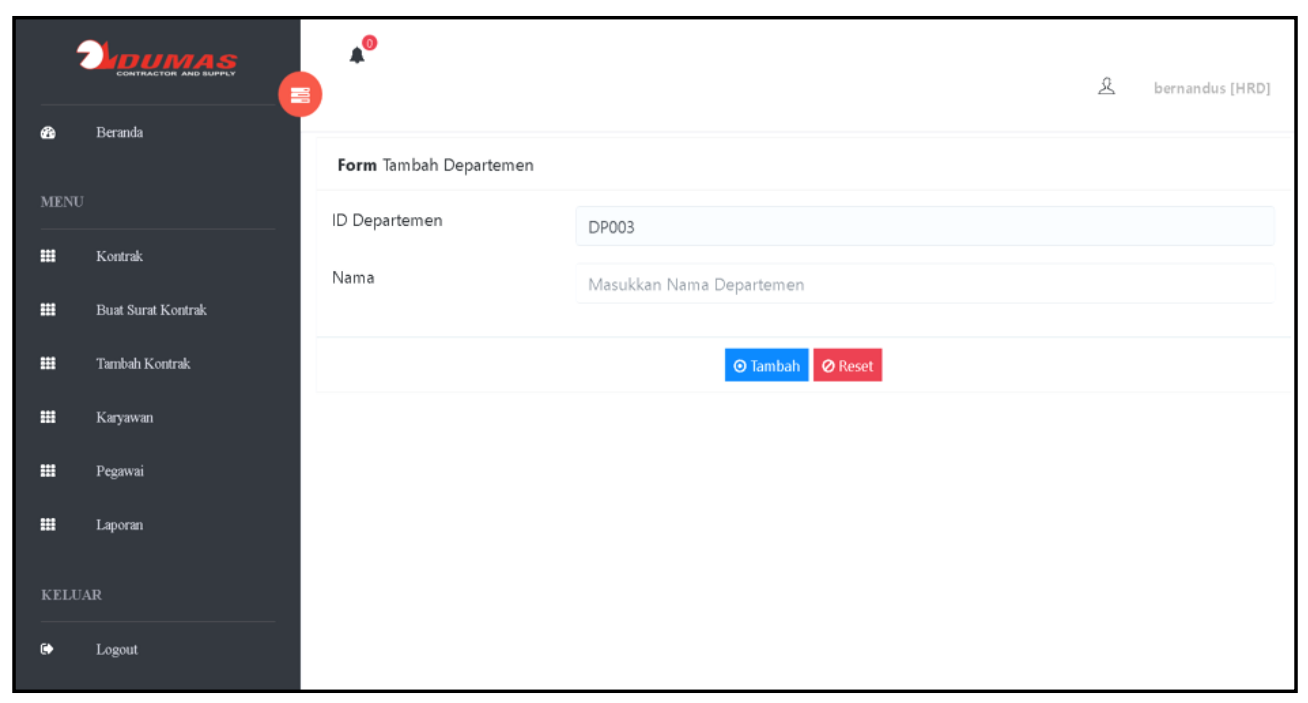

Gambar 12.Tampilan Halaman Input Departemen

Tampilan diatas adalah tampilan dari halaman Input Departemen.

\section{KESIMPULAN}

Berdasarkan pembahasan yang telah diuraikan pada bab sebelumnya terhadap sistem yang berjalan saat ini pada HRD PT. Putra Dumas lestari khusunya dalam proses penyusunan data kontrak karyawan maka peneliti dapat mengambil kesimpulan bahwa :

1. Dengan ada nya sistem yang dibuat oleh peneliti, pengolahan data kontrak karyawan yang sebelumnya membutukan waktu 2 hari kerja sekarang menjadi lebih cepat dan membutukan waktu kurang lebih 1 jam.

2. Sistem yg dibuat oleh penelitih, dalam menu data kontrak menginfokan batas waktu kontrak kerja dengan warna : warna kuning batas waktu kontrak kerja tinggal 15 hari lagi, warna merah batas waktu kontrak kerja sudah habis, dan, warna hitam batas waktu kontrak kerja masih lama.

3. Untuk merancang sistem manajemean administrasi dan pengingat kontrak karyawan yang sesuai dengan kebutuan perusahan dengan mengunakan matode analisa pieces dan bahasa pemograman PHP dan database mysql.

\section{SARAN}

Untuk meningkatkan atau memaksimalkan sistem informasi absensi berbasis web pada penelitian ini, saran yang dapat digunakan sebagai bahan pertimbangannya adalah sebagai berikut :

1. Agar tidak terjadi kesalahan dalam pembuatan kontrak di sarankan HRD mengkonfirmasi ulang.

2. Agar lebih efektif dan efisien di sarankan HRD untuk mengecek sistem dua kali dalam satu bulan.

3. Seiring dengan perkembangan jaman dan semakin canggih teknologi yang ada, maka sistem pengingat kontrak ini dapat dikembangkan lagi di masa yang akan datang dengan berbasis android. 


\section{DAFTAR PUSTAKA}

[1] Sutopo, Priyo, Dedi Cahyadi dan Zainal Arifin. 2016. Sistem Informasi Eksekutif Sebaran Penjualan Kendaraan Bermotor Roda 2 di Kalimantan Timur Berbasis Web. Jurnal Informatika Mulawarman. Vol.11 No.1-Februari 2016.

[2] M.thoha, miyanto. 2015. Analisis dan perancangan sistem reservasi hotel D'Griya Serang. Jurnal Psosisko. Vol.2 No.2.

[3] Ahmad Kausar,Yusuf Fazri Setiawan,Vidilia Rosalina. 2015. Perancangan Video Company Profile Kota Serang Dengan Teknik Editing Menggunakan Adobe Premire Pro Cs5. Jurnal PROSISKO ISSN : 2406-7733 Vol. 2 No. 1 Universitas Serang Raya Kota Serang Banten.

[4] Sukamto, Rosa Ariani dan Mutia Shalahuddin. 2014. Rekayasa Perangkat Lunak Terstruktur dan Berorientasi Objek. Bandung: Informatika.

[5] Maimunah, Dini Luigi, Ade Ferdiansyah .2017. RANCANG BANGUN SISTEM PELAYANAN DATA PELANGGAN (XIBAR) BERBASIS ONLINE. Yogyakarta: STMIK AMIKOM.

[6] Andi Prastomo. 2014. "Prototipe Sistem E-Learning Dengan Pendekatan Elisitasi Dan Framework Codeigniter: Studi Kasus SMP YAMAD BEKASI." Faktor Exacta 2: 7.

[7] Andreas Andoyo, and Tri Lestari. 2014. "Perancangan Model Pembayaran Pajak Kendaraan Berbasis Web Pada Kantor Samsat Pringsewu." Technology Acceptance Model 2.

[8] Anisah, Nurlaili, Anton, Ummu Radiyah. 2016. "rancangan sistem informasi erecruitment berbasis web pada PT.Geoservices." PROSISKO 2.

[9] Bayu Adi, Dwi Ananda, and Melani Trinawati. 2014. "Perancangan Sistem Informasi Penggajian Karyawan Berbasis Web Pada PT. Akses Nusa Karya Infratek." Technolongy 3: 1 .

[10] Hamidah, Hamidah, Eko Purnomo, and Moh Faid Moh Faid. "SISTEM APLIKASI PENGOLAHAN DATA KONTRAK MATERIAL DAN JASA BERBASIS WEB DI KOPKAR MITRA ENERGI SEJAHTERA PAITON." SENTIA 2016 8, no. 1 (2016).

[11] Hosseini, Asrin, Ahmadi, Amir Sheikh-Ahmadi. 2015. "Predicting Fault in the Process of Producing Important Android Aplications using Data Mining Techniques." Computer Applications 131: 13.

[12] Lubis, Rina Safitri. "DATA MINING PENGARSIPAN DOKUMEN BERDASARKAN KONTRAK KERJA DENGAN METODE ALPHABETIC FILING SYSTEM (Studi Kasus: PT. Arina Multi Karya Medan)." Majalah Ilmiah INTI (Informasi dan Teknologi Ilmiah) 4, no. 1 (2014). 